15

\title{
Использование эффекта отрицательного магнитосопротивления в кремнии для создания многофункциональных датчиков
}

\author{
() М.К. Бахадырханов, Х.М. Илиев, Г.Х. Мавлонов, Ш.Н. Ибодуллаев , С.А. Тачилин \\ Ташкентский государственный технический университет, Ташкент, Узбекистан \\ ฯ E-mail: shakhboz.ibodullayev.92@inbox.ru
}

Поступило в Редакцию 1 апреля 2021 г.

В окончательной редакции 14 июня 2021 г.

Принято к публикации 17 июня 2021 г.

\begin{abstract}
Установлено, что особенностью отрицательного магнитосопротивления в кремнии, содержащем нанокластеры атомов марганца, является его высокая чувствительность к различным внешним воздействиям. Определены закономерности изменения отрицательного магнитосопротивления в кремнии, содержащем нанокластеры атомов марганца, в зависимости от температуры, освещенности, величины электрического и магнитного полей. Показана возможность создания нового класса многофункциональных датчиков физических величин на основе единого кристалла кремния, содержащего нанокластеры атомов марганца.
\end{abstract}

Ключевые слова: многофункциональный датчик, отрицательное магнитосопротивление, кремний, нанокластер, марганец.

DOI: 10.21883/PJTF.2021.19.51504.18799

В настоящее время датчики для контроля и измерения физических величин широко применяются в различных областях науки и техники [1]. Для контроля и измерения температуры, освещенности, давления, магнитного и электрического полей используются отдельные датчики, изготовленные на основе разных полупроводниковых материалов [2]. При использовании различных датчиков в одной системе (медицина, роботы, системы автоматизации и т.д.) для их нормального функционирования необходимо решить ряд технических проблем, связанных со взаимным согласованием работы нескольких датчиков, расположением их в системе, обеспечением необходимой энергией, а также другими факторами. Также следует отметить, что использование достаточно большого числа датчиков различного назначения приводит к увеличению габаритов и массы приборов и устройств. Поэтому определенный научный и практический интерес представляют разработка и создание многофункциональных датчиков для измерения и контроля различных физических величин (температура, освещение, давление, магнитное поле). В этом плане интересны работы $[3,4]$, в которых авторы показали возможность создания многофункциональных датчиков на основе гибридных микросборок. Нам кажется, что это требует не только достаточно сложных схемотехнических, но и трудоемких технологических решений и операций.

Целью настоящей работы является использование особенностей магнитных свойств кремния, легированного марганцем, т.е. отрицательного магнитосопротивления (ОМС), для создания многофункциональных датчиков физических величин. Как было показано ранее [5-7], при определенных термодинамических условиях легирования в кристаллической решетке кремния формируются магнитные нанокластеры, состоящие из четырех ионов марганца $\left(\mathrm{Mn}^{++}-4 s^{2} 3 d^{5}\right)$, находящихся в ближайших междоузельных состояниях вокруг иона бора $\left(\mathrm{B}^{-}\right)$, их наличие стимулирует появление аномально высокого отрицательного магнитосопротивления при $T=300 \mathrm{~K}$ [8], которое практически отсутствует во многих других магнитных полупроводниковых материалах.

В настоящее время нами показана возможность использования особенностей эффекта ОМС в кремнии для создания нового класса многофункциональных датчиков на основе единого кристалла. В качестве исходного материала был использован монокристаллический кремний $p$-типа проводимости с $\rho=3 \Omega \cdot \mathrm{cm}$ (КДБ-3) размером $8 \times 3 \times 0.6 \mathrm{~mm}$. Согласно работе [9], условия легирования образцов были такими, что после диффузии марганца образцы оставались $p$-типа проводимости с удельным сопротивлением $\rho=(5-8) \cdot 10^{3} \Omega \cdot \mathrm{cm}$ при $T=300 \mathrm{~K}$. После диффузии образцы подвергались механической и химической обработке для удаления с поверхности образца различных дефектов и слоя, обогащенного марганцем. Электрические параметры были исследованы методом эффекта Холла.

Было изучено влияние внешнего магнитного поля на электрофизические параметры кремния с нанокластерами атомов марганца, измерения проводились при комнатной температуре при поперечном $(\mathbf{B} \perp \mathbf{I})$ направлении магнитного поля по отношению к электрическому току, протекающему через образец. Напряженность магнитного поля изменялась в интервале $B=0-1.8 \mathrm{~T}$, т. е. выполнялось условие слабого магнитного поля. В отличие от других магнитных полупроводников в исследуемых образцах проводимость при наличии магнитного поля не уменьшается, а, наоборот, существенно увеличивается, т.е. при комнатной температуре наблюдается эффект аномально высокого ОМС. Такие эффекты в 
Таблица 1. Электрические параметры исследуемых образцов при $T=300 \mathrm{~K}$

\begin{tabular}{c|c|c|c|c}
\hline Номер образца & $\begin{array}{c}\text { Удельное } \\
\text { сопротивление } \\
\rho, \Omega \cdot \mathrm{cm}\end{array}$ & $\begin{array}{c}\text { Концентрация } \\
\text { носителей заряда } \\
p, n, \mathrm{~cm}^{-3}\end{array}$ & $\begin{array}{c}\text { Подвижность } \\
\text { носителей заряда } \\
\mu, \mathrm{cm}^{2} /(\mathrm{V} \cdot \mathrm{s})\end{array}$ & $\begin{array}{c}\text { Магнитосопротивление } \\
\Delta \rho / \rho_{0}, \% \\
(\text { при } 100 \mathrm{~V} / \mathrm{cm})\end{array}$ \\
\hline 1 & $5.0 \cdot 10^{3}$ & $1.30 \cdot 10^{13}$ & 70 & -350 \\
2 & $6.3 \cdot 10^{3}$ & $1.80 \cdot 10^{13}$ & 55 & -220 \\
3 & $5.8 \cdot 10^{4}$ & $1.60 \cdot 10^{12}$ & 64 & -64 \\
4 & $2.0 \cdot 10^{5}$ & $1.40 \cdot 10^{11}$ & 184 & 6 \\
5 & $2.5 \cdot 10^{5}$ & $2.55 \cdot 10^{10}$ & 980 & 6
\end{tabular}

других полупроводниках наблюдались при более низких температурах $(T<100 \mathrm{~K})$, а значение установленного ОМС достигало величины $\Delta \rho / \rho_{0} \sim 4-5 \%$ [10].

В табл. 1 приведены электрические параметры полученных образцов, а также их максимальное значение ОМС при $T=300 \mathrm{~K}$. Видно, что в таких образцах наблюдаются низкое значение подвижности и аномально большие значения ОМС, что подтверждают результаты работы [11]. Установлено, что действительно во всех компенсированных образцах, легированных марганцем, с удельным сопротивлением $\rho=(5-8) \cdot 10^{3} \Omega \cdot \mathrm{cm}$ наблюдается аномально большое ОМС при $T=300 \mathrm{~K}$. С ростом удельного сопротивления $\rho>10^{4} \Omega \cdot \mathrm{cm}$ значение ОМС уменьшается, а в перекомпенсированных образцах $n$-типа проводимости независимо от их удельного сопротивления наблюдается только небольшое положительное магнитосопротивление. Поэтому в дальнейших исследованиях были использованы только образцы $p$-типа проводимости с $\rho=(5-8) \cdot 10^{3} \Omega \cdot \mathrm{cm}$. При исследовании было обнаружено, что значение ОМС в полученном материале существенно зависит от температуры, освещенности (как фонового света, так и ИК-излучения) и электрического поля при наличии постоянного магнитного поля. Именно этот интересный эффект стимулировал создание многофункционального датчика.

На рис. 1 представлены зависимости значения ОМС полученных образцов от величины магнитного поля в интервале $B=0.05-1.8 \mathrm{~T}$ при $T=300 \mathrm{~K}$. Видно, что c ростом магнитного поля значение ОМС монотонно увеличивается и достигает максимального значения $\Delta \rho / \rho_{0}=220-300 \%$. В исследуемой области магнитного поля магниточувствительность при $T=300 \mathrm{~K}$ составляет более $\alpha=100 \% /$ T. Это довольно высокая магниточувствительность для полупроводникового материала при $T=300 \mathrm{~K}$, что показывает возможность создания магнитодатчиков на основе полученного материала.

На рис. 2, а представлена температурная зависимость ОМС исследуемых образцов в интервале температур $T=240-300 \mathrm{~K}$ в отсутствие освещения при постоянном значении электрического и магнитного полей. Как видно, с понижением температуры значение ОМС почти монотонно увеличивается и при $T=240 \mathrm{~K}$ составляет $\Delta \rho / \rho_{0} \sim 600 \%$. Расчет показывает, что температурная

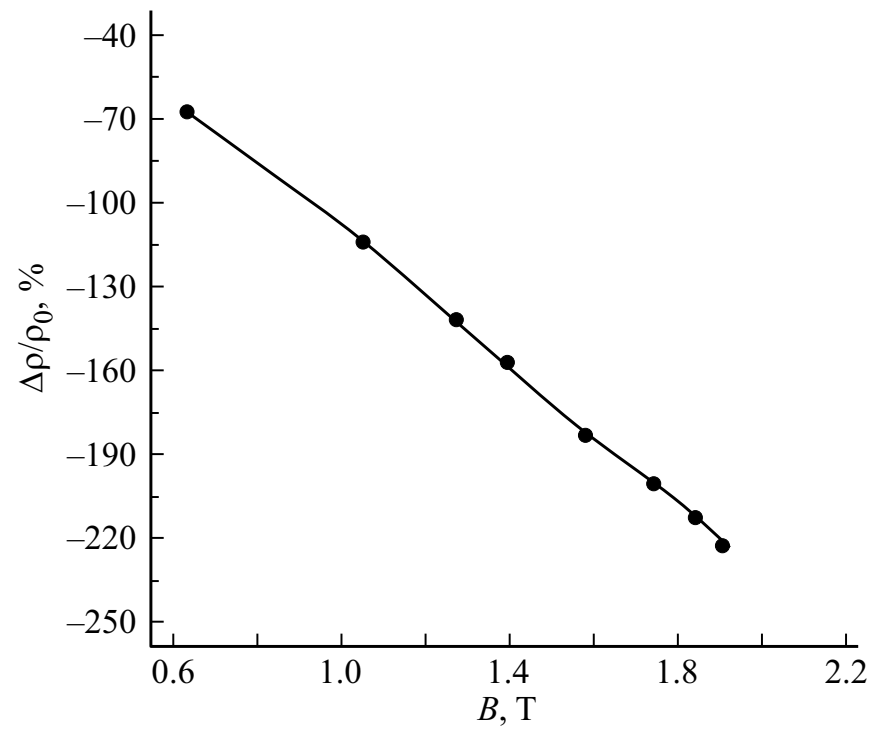

Рис. 1. Зависимость ОМС от магнитного поля.

чувствительность ОМС в образцах в исследуемом интервале температур составляет $\beta=7-8 \% / \mathrm{K}$. Это означает, что можно создать достаточно высокочувствительный и быстродействующий термодатчик на основе изменения $\mathrm{OMC}$ в $\mathrm{Si}\langle\mathrm{Mn}, \mathrm{B}\rangle$.

Исследование влияния достаточно низкого уровня освещения светом спектра видимого диапазона на значение ОМС при $T=300 \mathrm{~K}$ показало, что освещение образцов приводит к уменьшению ОМС. На рис. $2, b$ представлена зависимость ОМС от интенсивности освещения лампой накаливания в интервале $I=5-401 \mathrm{x}$. Измерения проводились при наличии фоновой освещенности, не устраняемой слабой постоянной засветки образцов ИК-светом малой интенсивности, источником которой являются различные внешние нагретые объекты. Видно, что освещение образцов приводит к существенному изменению ОМС. Расчет показал, что чувствительность $\Delta \rho / \rho_{0}$ при этом составляет $\gamma=2-2.5 \% / 1 \mathrm{x}$. Полученные результаты показывают, что на основе ОМС в $\mathrm{Si}\langle\mathrm{Mn}, \mathrm{B}\rangle$ можно создать достаточно чувствительный фотодатчик, работающий при низкой интенсивности света при $T=300 \mathrm{~K}$. 

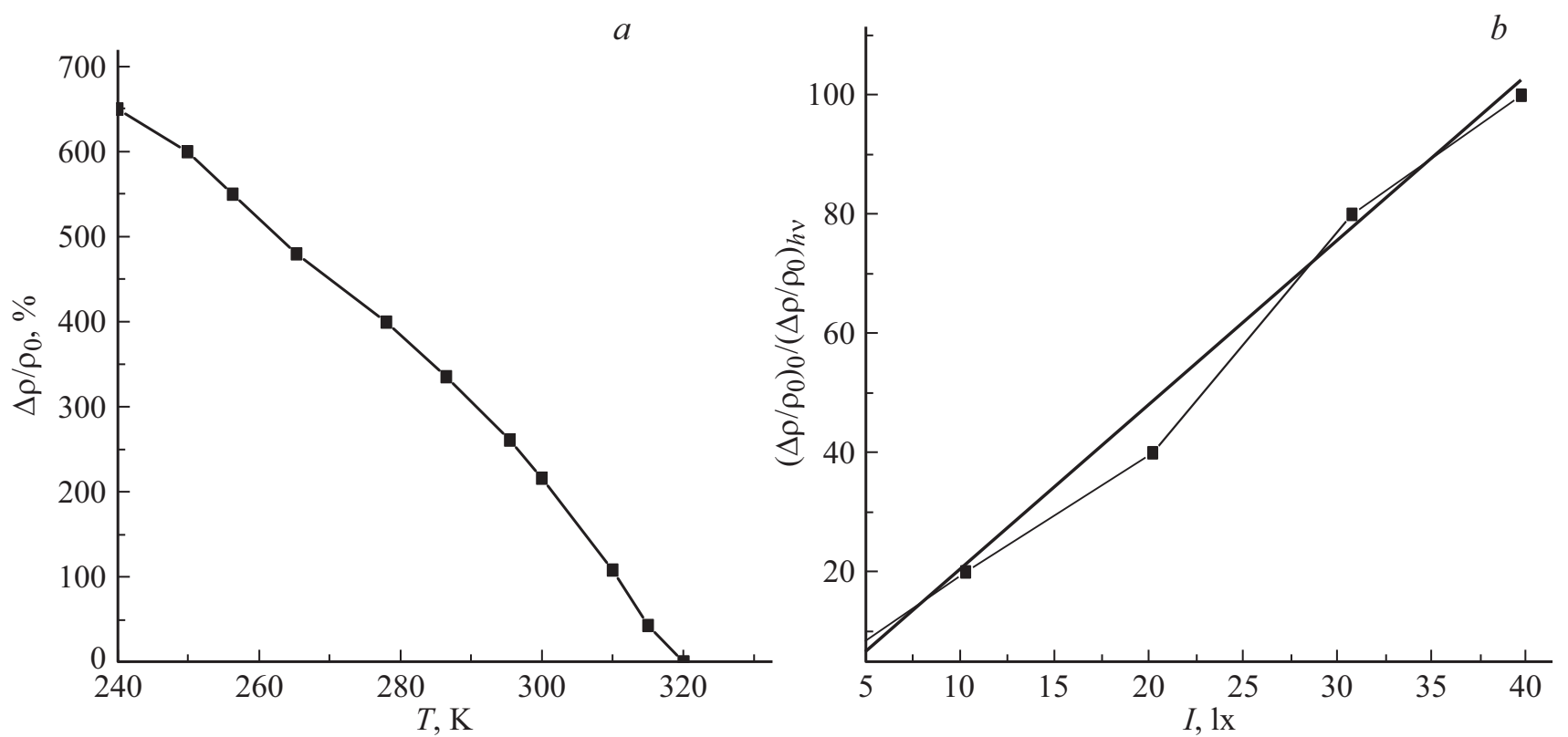

Рис. 2. $a-$ зависимость ОМС от температуры; $b-$ зависимость ОМС от интенсивности света видимого диапазона $\left(\Delta \rho / \rho_{0}\right)_{h v}$ относительно темнового значения $\left(\Delta \rho / \rho_{0}\right)_{0}$.
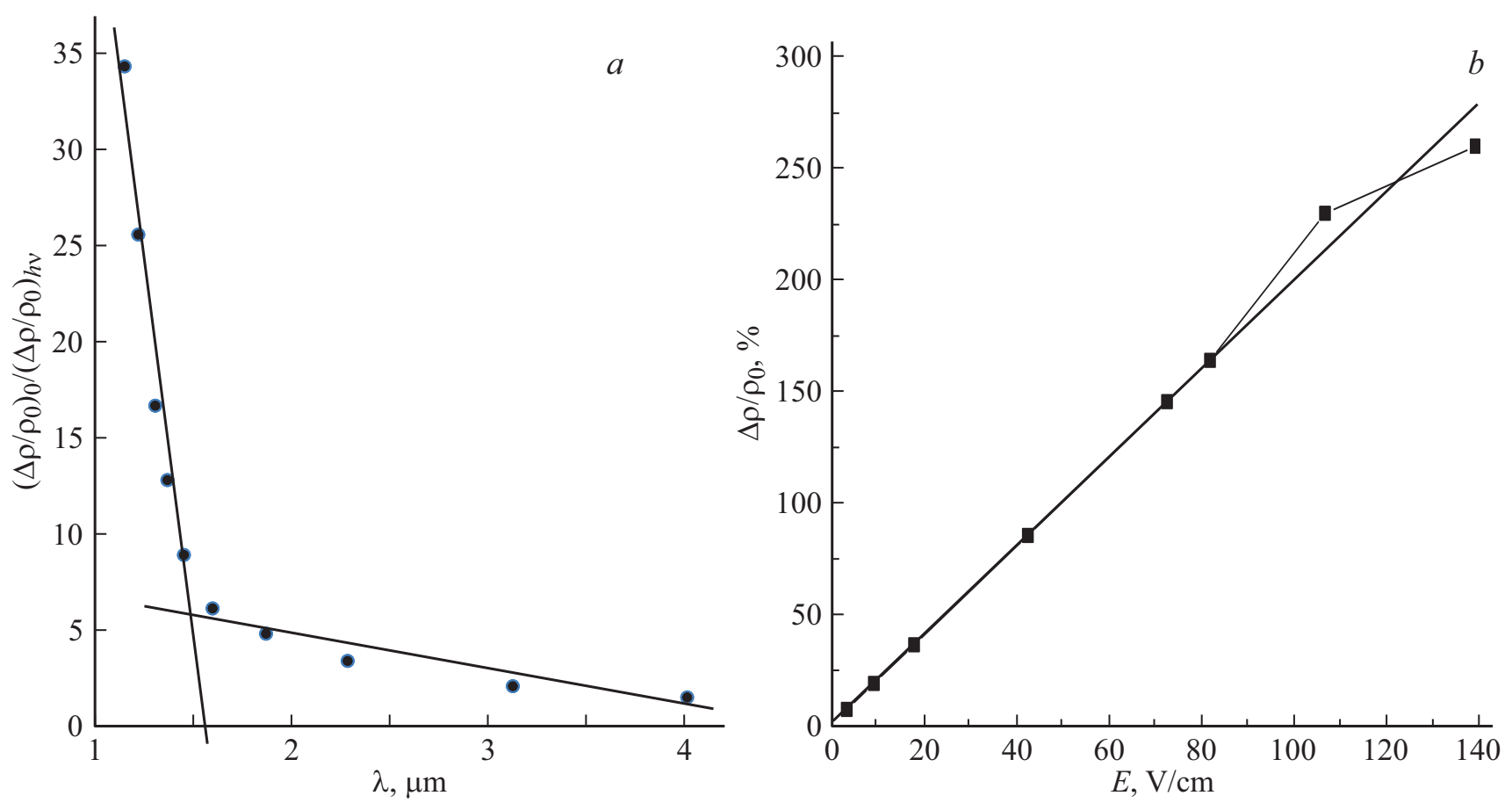

Рис. 3. $a-$ спектральная ИК-зависимость ОМС $\left(\Delta \rho / \rho_{0}\right)_{h v}$ относительно темнового значения $\left(\Delta \rho / \rho_{0}\right)_{0} ; b-$ зависимость ОМС от электрического поля.

На рис. 3, $a$ представлено относительное изменение ОМС при попадании ИК-света в интервале $\lambda=1.2-4 \mu \mathrm{m}$, а именно спектральная ИК-зависимость ОМС $\left(\Delta \rho / \rho_{0}\right)_{h v}$ относительно темнового значения $\left(\Delta \rho / \rho_{0}\right)_{0}$. Как видно, в области ИК-спектра с $\lambda=1.2-4 \mu \mathrm{m}$ с увеличением энергии фотонов падающего ИК-излучения значение ОМС существенно уменьшается (почти в 30-35 раз) с чувствительностью $\beta=10-15 \% / \mu \mathrm{m}$ при мощности ИК-света $P=10^{-6} \mathrm{~W}$ и $T=300 \mathrm{~K}$. В интервалах $\lambda=1.2-1.5$ и $1.5-4 \mu \mathrm{m}$ магнитосопротивление уменьшается с различной закономерностью. Установлено, что при уменьшении мощности ИК-излучения до $P=10^{-9} \mathrm{~W}$ характер изменения ОМС остается таким же, как и при $P=10^{-6} \mathrm{~W}$. Эти 
Таблица 2. Основные параметры разработанного многофункционального датчика на основе отрицательного магнитосопротивления в кремнии, легированном марганцем, при $T=300 \mathrm{~K}$

\begin{tabular}{|c|c|c|c|c|c|}
\hline \multirow[b]{2}{*}{ Параметр } & \multicolumn{5}{|c|}{ Внешнее воздействие } \\
\hline & $\begin{array}{c}\text { Магнитное поле } \\
B=0.05-1.8 \mathrm{~T}\end{array}$ & $\begin{array}{c}\text { Температура } \\
T=240-320 \mathrm{~K}\end{array}$ & $\begin{array}{c}\text { Свет спектра видимого } \\
\text { диапазона с интен- } \\
\text { сивностью } I=5-401 x\end{array}$ & $\begin{array}{c}\text { ИК-излучение } \\
(\lambda=1.2-4 \mu \mathrm{m}) \\
\text { мощностью } P=10^{-6} \mathrm{~W}\end{array}$ & $\begin{array}{c}\text { Электрическое } \\
\text { поле } 5-140 \mathrm{~V} / \mathrm{cm}\end{array}$ \\
\hline Чувствительность $\Delta \rho / \rho_{0}$ & $95-107 \% / \mathrm{T}$ & $7-8 \% / \mathrm{K}$ & $2-2.5 \% / 1 \mathrm{x}$ & $10-15 \% / \mu \mathrm{m}$ & $2-2.5 \% /(\mathrm{V} / \mathrm{cm})$ \\
\hline Быстродействие, ms & $20-25$ & $25-30$ & $10-15$ & $15-20$ & $10-15$ \\
\hline
\end{tabular}

данные позволяют использовать ОМС в кремнии, легированном марганцем, для создания достаточно чувствительных ИК-датчиков в интервале $\lambda=1.2-4 \mu \mathrm{m}$.

Экспериментально установлено, что значение ОМС существенно увеличивается с ростом приложенного электрического поля в отсутствие любого типа освещения при $T=300 \mathrm{~K}$. Данная экспериментальная зависимость, усредненная прямой линией, представлена на рис. $3, b$. Как видно из этого рисунка, с ростом значения электрического поля значение ОМС практически монотонно увеличивается. На основе полученных результатов установлено, что чувствительность ОМС к электрическому полю составляет $2-2.5 \% /(\mathrm{V} / \mathrm{cm})$.

Таким образом, на основе экспериментальных данных было установлено, что в кремнии с магнитными нанокластерами $p$-типа с $\rho=(5-8) \cdot 10^{3} \Omega \cdot \mathrm{cm}$ при комнатной температуре наблюдается аномально большое значение ОМС, которое отсутствует в других магнитных полупроводниковых материалах [12-14]. Особенность наблюдаемого ОМС в полученных образцах заключается в том, что значение ОМС существенно зависит не только от магнитного поля, но и от температуры, интенсивности освещения ИК-излучения в области $\lambda=1.2-4 \mu \mathrm{m}$, а также электрического поля. Определено, что чувствительность ОМС к различным внешним воздействиям составляет 7-8\%/K для температуры, 2-2.5\%/(V/cm) для электрического поля и 95-107\%/Т для магнитного поля, $2-2.5 \% / 1 \mathrm{x}$ для интенсивности освещения светом спектра видимого диапазона и $10-15 \% / \mu \mathrm{m}$ для ИК-излучения в области $\lambda=1.2-4 \mu \mathrm{m}$. В табл. 2 представлены основные параметры изготовленных датчиков при наличии внешних воздействий $(T=300 \mathrm{~K})$. Такой интересный эффект наблюдался во всех образцах $\mathrm{Si}\langle\mathrm{Mn}, \mathrm{B}\rangle$ с $\rho=(5-8) \cdot 10^{3} \Omega \cdot \mathrm{cm}$ независимо от их размеров. Данный эффект позволяет создать новый класс многофункциональных датчиков на основе единого кристалла кремния с нанокластерами атомов марганца, работающих в интервале температур $T=240-320 \mathrm{~K}$, с довольно высокой чувствительностью.

\section{Финансирование работы}

Работа выполнена в 2017-2020 гг. в рамках проекта ОТ-Ф2-55 „Разработка научных основ получения объем- нонаноструктурированного кремния на основе формирования нанокластеров примесных атомов как нового класса наноматериалов с уникальными функциональными возможностями“.

\section{Конфликт интересов}

Авторы заявляют, что у них нет конфликта интересов.

\section{Список литературы}

[1] В.М. Шарапов, Е.С. Полищук, Н.Д. Кошевой, Г.Г. Ишанин, И.Г. Минаев, А.С. Совлуков, Датчики. Справочное пособие (Техносфера, М., 2012).

[2] Б. Топильский, Микроэлектронные измерительные преобразователи (БИНОМ. Лаборатория знаний, М., 2013).

[3] Е.А. Ломтев, П.Г. Михайлов, А.У. Аналиева, А.О. Сазонов, Измерение. Мониторинг. Управление. Контроль, 2 (12), 57 (2015).

[4] А.А. Дружинин, А.П. Кутраков, Н.С. Лях-Кагуй, А.М. Вуйцик, Технология и конструирование в электронной аппаратуре, № 4, 23 (2013).

[5] S.K. Bux, R.G. Blair, P.K. Gogna, H. Lee, G. Chen, M.S. Dresselhaus, R.B. Kaner, J.P. Fleurial, Adv. Funct. Mater., 19, 2445 (2009). DOI: 10.1002/ADFM.200900250

[6] В.И. Фистуль, В.М. Казакова, Ю.А. Бобриков, А.В. Рябцев, К.П. Абдурахманов, С. Зайнабидинов., Т.С. Камилов, Ш.Б. Утамурадова, ФТП, 16 (5), 939 (1982).

[7] G.W. Ludwig, H.H. Woodbury, R.O. Carlson, J. Phys. Chem. Solids, 8, 490 (1959).

[8] М.К. Бахадырханов, К.С. Аюпов, Г.Х. Мавлонов, С.Б. Исамов, ФТП, 44 (9), 1181 (2010). [M.K. Bakhadyrkhanov, K.S. Ayupov, G.Kh. Mavlyanov, S.B. Isamov, Semiconductors, 44 (9), 1145 (2010). DOI: 10.1134/S106378261009006X].

[9] М.К. Бахадырханов, Г.Х. Мавлонов, С.Б. Исамов, Х.М Илиев, К.С. Аюпов, 3.М. Сапарниязова, С.А. Тачилин, Неорган. материалы, 47 (5), 545 (2011). [M.К. Bakhadyrkhanov, G.Kh. Mavlonov, S.B. Isamov, Kh.M. Iliev, K.S. Ayupov, Z.M. Saparniyazova, S.A. Tachilin, Inorgan. Mater., 47 (5), 479 (2011). DOI: $10.1134 / \mathrm{S} 0020168511050062]$.

[10] М.К. Бахадырханов, Г.Х. Мавлонов, Х.М. Илиев, К.С. Аюпов, О.Э. Саттаров, С.А. Тачилин, ФТП, 48 (8), 1014 (2014). [M.K. Bakhadirkhanov, G.H. Mavlonov, X.M. Iliev, K.S. Ayupov, O.E. Sattarov, C.A. Tachilin, Semiconductors, 48 (8), 986 (2014). DOI: 10.1134/S106378261408003X]. 
[11] М.К. Бахадырханов, Х.М. Илиев, Г.Х. Мавлонов, К.С. Аюпов, С.Б. Исамов, С.А. Тачилин, ЖТФ, 89 (3), 421 (2019). DOI: 10.21883/JTF.2019.03.47179.184-18

[M.K. Bakhadyrkhanov, Kh.M. Iliev, G.Kh. Mavlonov, K.S. Ayupov, S.B. Isamov, S.A. Tachilin, Tech. Phys., 64 (3), 385 (2019). DOI: 10.1134/S1063784219030046].

[12] Л.И. Королёва, И.К. Баташев, А.С. Морозов, А.М. Балбашов, H. Szymczak, ЖТФ, 88 (2), 228 (2018). DOI: $10.21883 /$ JTF.2018.02.45413.2358 [L.I. Koroleva, I.K. Batashev, A.S. Morozov, A.M. Balbashov, H. Szymczak, A. Slawska-Waniew, Tech. Phys., 63(2), 220 (2018). DOI: $10.1134 / \mathrm{S} 1063784218020202]$.

[13] В.В. Устинов, А.Б. Ринкевич, Л.Н. Ромашев, Д.В. Перов, ЖТФ, 74 (5), 94 (2004). [V.V. Ustinov, A.B. Rinkevich, L.N. Romashev, D.V. Perov, Tech. Phys., 49 (5), 613 (2004). DOI: $10.1134 / 1.1758338]$.

[14] А.С. Газизулина, А.А. Насиров, А.А. Небесный, П.Б. Парчинский, Dojin Kim, ФТП, 55 (2), 159 (2021). DOI: 10.21883/FTP.2021.02.50503.9502 [A.S. Gazizulina, A.A. Nasirov, A.A. Nebesniy, P.B. Parchinskiy, Dojin Kim, Semiconductors, 55 (2), 214 (2021).

DOI: $10.1134 / \mathrm{S} 1063782621020123]$. 